\title{
Using Metaphors to Explore Cultural Perspectives in Cross-Cultural Design
}

\author{
Luciana Cardoso de Castro Salgado, Clarisse Sieckenius de Souza, \\ and Carla Faria Leitão \\ Departamento de Informática - PUC-Rio - Rua Marquês de São Vicente, 225 \\ RDC CEP 2451-900 - Gávea - Rio de Janeiro RJ - Brasil \\ \{lsalgado, Clarisse, cfaria\} @inf.puc-rio.br
}

\begin{abstract}
We have proposed five cultural viewpoint metaphors to help designers that wish to encourage and support cross-cultural HCI contacts. In this paper we present the main results of an experiment carried out to assess the potential of these metaphors in designing cross-cultural systems. Six HCI designers, with different cultural backgrounds, were then asked to create re-design alternatives for a real website guided by the metaphors. As a result, the experiment showed the epistemic effect of the metaphors on cross-cultural design, i. e. as a means to build new knowledge and understanding.
\end{abstract}

Keywords: Cross-cultural design; HCI and Culture; Conceptual metaphors for HCI design.

\section{Introduction}

Today, one of the challenges for interaction design is the development of systems aiming to attend to the needs and expectations of people with different cultural and social backgrounds. The most widely used perspective adopted in cross-cultural design is internationalization-localization (Int-Loc) $[1,6,7,9]$. Internationalization is the process of preparing code that separates the core functionality of the system from interface specifics (e.g. text language, measures, etc.) [7]. With localization, the interface is customized for a particular audience (through language translation, cultural markers and even technical features, for instance) [9].

We are, however, interested in another kind of context: one where the design intent is to expose and explore cultural diversity, rather than conceal it. This is the case, for instance, when the purpose of the designed system is to stimulate the users to make contact with a foreign culture. In this paper we briefly describe five cultural viewpoint metaphors (CVM) [12], a conceptual design tool that can be used when cross-cultural system designers explicitly want to support and promote different levels of contact with cultural diversity. The International Children's Digital Library ${ }^{1}$ and the Unesco ${ }^{2}$ websites are examples of systems that fall in this category.

\footnotetext{
${ }^{1}$ http://en.childrenslibrary.org/ last accessed in Feb 3, 2011.

${ }^{2} \mathrm{http} / / /$ www.unesco.org/new/en/unesco/ last accessed in Feb 3, 2011.
} 
CVM derived from empirical studies applying Semiotic Engineering [5] to analyze and re-design cross-cultural systems interfaces. This theory views human-computer interaction as a computer-mediated human communication process, with three communicating agents on stage: designers, users and system. They are brought together at interaction time through metacommunication. In this particular process, through interface content and controls, the designers actually send an interactive message to users, implicitly telling them about who the designers think the users are, what they have learned about the users' needs and expectations, and finally how and why the users can explore communication with the system while aiming to achieve a wide range of envisaged goals.

This paper aims at presenting an empirical experiment carried out to assess the potential of CVM in designing for cross-cultural experience. The main results reveal the epistemic value of CVM on cross-cultural design at helping designers to think of how to expose and communicate the very idea of cultural diversity. They also suggest that this specific approach to culture-sensitive HCI design deserves attention.

The experiment is, actually, part of broader two-step case study. One, which is presented in this paper, assessed how CVM can be used at design time, and the other assessed how CVM can be used at evaluation time. We triangulated results from the case study with results from another experiment with CVM at evaluation time carried out in another domain. The whole case study is presented in [13].

We begin by briefly presenting the cultural viewpoint metaphors in Section 2. In Section 3, we describe and present results from the experiment with CVM at design time. Finally, in Section 4, we discuss the value of our findings for cross-cultural HCI design.

\section{Cultural Viewpoint Metaphors as a Top Level Frame for Cross-Cultural Hci Design}

The cultural viewpoint metaphors defined in [12] lead designers to conceive of users primarily as travelers. Designers can make decisions about if and how it is appropriate to expose the users to content from other cultures while interacting with a cross-cultural system. Like all other conceptual design metaphors, they have been directly influenced by Lakoff and Johnson's view that a metaphor "is a way of conceiving of one thing in terms of another, and its primary function is understanding" [8].

The metaphors express five distinct perspectives on traveling through a crosscultural territory, and can be plotted upon a continuum of cultural approximation established with reference to a presumed user's own native culture. They span from cultural isolation (the domestic traveler metaphor) to complete cultural immersion (the foreigner without translator metaphor). In between these two extremes there are three metaphors marking progressive cultural approximation: the observer at a distance, the guided tour visitor, and the foreigner with translator metaphors (see Fig. 1). 


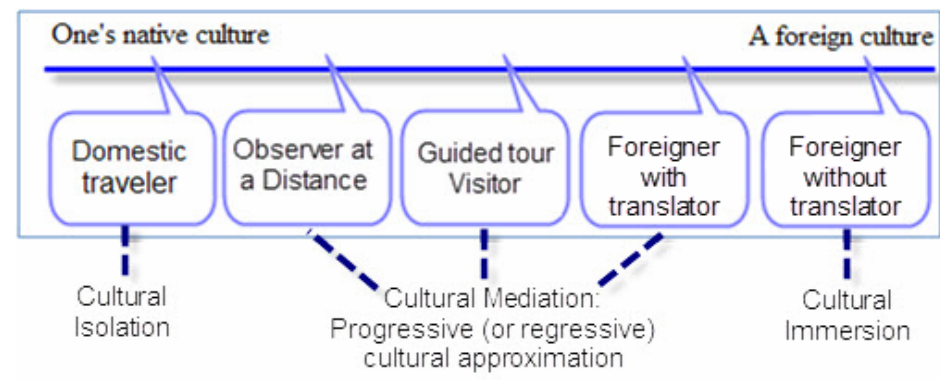

Fig. 1. Progressive cultural viewpoint metaphors

Table 1. Metaphors expression and the effects on organization of Interactive Discourse

\begin{tabular}{|c|c|c|c|}
\hline \multirow{3}{*}{ Metaphor Expression } & \multicolumn{3}{|c|}{ Effects on organization of Interactive Discourse } \\
\hline & \multirow{2}{*}{$\begin{array}{l}\text { Metacommunication } \\
\text { features }\end{array}$} & \multicolumn{2}{|c|}{ Cultural variables } \\
\hline & & Language & $\begin{array}{l}\text { Cultural } \\
\text { Practice }\end{array}$ \\
\hline $\begin{array}{l}\text { DOMESTIC TRAVELER. No } \\
\text { markers from the foreign culture. }\end{array}$ & $\begin{array}{l}\text { Design neutralizes cultural } \\
\text { differences and makes the } \\
\text { user's culture dominate. }\end{array}$ & User's & User's \\
\hline $\begin{array}{l}\text { OBSERVER AT A DISTANCE. } \\
\text { The cultural markers of another } \\
\text { culture are communicated as } \\
\text { 'information' (not as an experience } \\
\text { the use can 'feel'). }\end{array}$ & $\begin{array}{l}\text { Interface elements which } \\
\text { represent cultural practices } \\
\text { are presented according to } \\
\text { the user's culture. } \\
\text { Narrative about the foreign } \\
\text { culture provides factual } \\
\text { information about what is } \\
\text { different from one's own } \\
\text { culture. }\end{array}$ & User's & User's \\
\hline $\begin{array}{l}\text { GUIDED TOUR VISITOR. } \\
\text { Cultural markers from another } \\
\text { culture are 'illustrated' to the user } \\
\text { (aspects of cultural issues are } \\
\text { exemplified and explained in the } \\
\text { user's language). }\end{array}$ & $\begin{array}{l}\text { Design provides contrast } \\
\text { between the two cultures. } \\
\text { An interpreted view and } \\
\text { commentary on the foreign } \\
\text { culture mediates the user's } \\
\text { approximation and } \\
\text { experience with cultural } \\
\text { diversity. The user's own } \\
\text { culture is dominant and } \\
\text { serves as reference. }\end{array}$ & User's & Foreign \\
\hline $\begin{array}{l}\text { FOREIGNER WITH } \\
\text { TRANSLATOR. Cultural markers } \\
\text { of another culture can be directly } \\
\text { 'experienced' by the user, although } \\
\text { in the user's own language. }\end{array}$ & $\begin{array}{l}\text { Communication content is } \\
\text { presented in the same way it } \\
\text { as to the native users from } \\
\text { the foreign culture. Only } \\
\text { linguistic translation is } \\
\text { done. }\end{array}$ & User's & Foreign \\
\hline $\begin{array}{l}\text { FOREIGNER WITHOUT } \\
\text { TRANSLATOR. Users are } \\
\text { addressed as a foreign culture's } \\
\text { natives. }\end{array}$ & $\begin{array}{l}\text { The culture of others is } \\
\text { offered as it is. }\end{array}$ & Foreign & Foreign \\
\hline
\end{tabular}


The adoption of each metaphor entails a different organization of the interactive discourse and different metacommunication features in design (See Table 1). They explicitly correspond to different combinations of values assigned to two global variables: language (the user's or foreign) and cultural practices (with several domaindependent values: for example, 'driving on the left-hand side of the road', 'reading pages from right to left', etc.). Decisions about how to combine these values $(e . g$. presenting the interface in the user's native language, but addressing the user with a foreign degree of formality) and how much explanation to give regarding foreign content selected by the designer, can achieve powerful communicative effects. The intended effect on the expression of design may be one or more of the following:

- Cultural isolation: by design, users are situated exclusively in their own culture, without being exposed to material explicitly referenced to a foreign culture (using the domestic traveler metaphor).

- Cultural mediation: by design, users experience different levels of contact with a foreign culture, from strong mediation to weak mediation:

oStrong mediation: users have only allusive references to a foreign culture, and their own culture dominates the interface signs and interaction forms (using the observer at a distance metaphor).

oIntermediate mediation: users are explicitly guided as they experience selected aspects of a foreign culture through interface signs and interaction forms borrowed from this culture's language(s) and social practices (using the guided tour visitor metaphor).

oWeak Mediation: users directly experience the cultural practices from a foreign culture through interface signs and interaction forms; only the users' native language is retained as a reference to his native culture (using the foreigner with translator metaphor).

- Cultural immersion: by design, users are fully exposed to a foreign culture's language and cultural practices, without translation or explanations for foreign interface signs and interaction forms (using the foreigner without translator metaphor).

Cross-cultural systems interfaces may be designed using one or more of the proposed metaphors. For instance, it may be desirable to adopt cultural isolation for certain tasks, while intentionally exposing the user to various degrees of foreignness in others. Whether the communication of relevant content is going to be expressed through the observer at a distance, guided tour visitor, foreigner with translator or foreigner without translator metaphor is a design choice. As a rule, the stronger the mediation, the higher the chances that users will get more and more selective bits of pre-filtered cross-cultural information (selected by design), getting increasingly farther from knowing what roles the information pragmatically plays in the context of the foreign culture involved. For instance, in e-commerce applications, the interface for payment tasks may be designed following the domestic traveler metaphor to avoid misunderstandings in transactions involving money. However, users might benefit from knowing that, unlike what happens in their native country, in the foreign country where the purchased goods are going to be delivered customers don't choose to have goods delivered at their homes. They prefer to redeem the goods at specific locations because transportation services cannot be trusted, for instance. 


\section{Using CVM at Design Time - An Experiment with Avis Website}

In order to investigate if and how CVM can support HCI professionals/practitioners at design time, we ran an empirical experiment with the AVIS Rent a Car System ${ }^{\odot}$ website $^{3}$. It is part of a broader case study to assess how CVM can be used both in design and evaluation activities. Among the larger set of results achieved with the case study [13], this paper discusses the epistemic effect of CVM in a re-design activity.

We chose the AVIS website because it was not elaborated with CVM, and it is clearly a cross-cultural application in the car rental domain that could be re-designed to promote cross-cultural contact. In it, we read that AVIS is "one of the world's leading car rental brands and operates in more than 2,100 locations in the United States, Canada, Australia, New Zealand, Latin America and the Caribbean region" They have a USA-based Global website with more than 50 localized versions for countries around the world such as China, for instance (see Fig. 2).

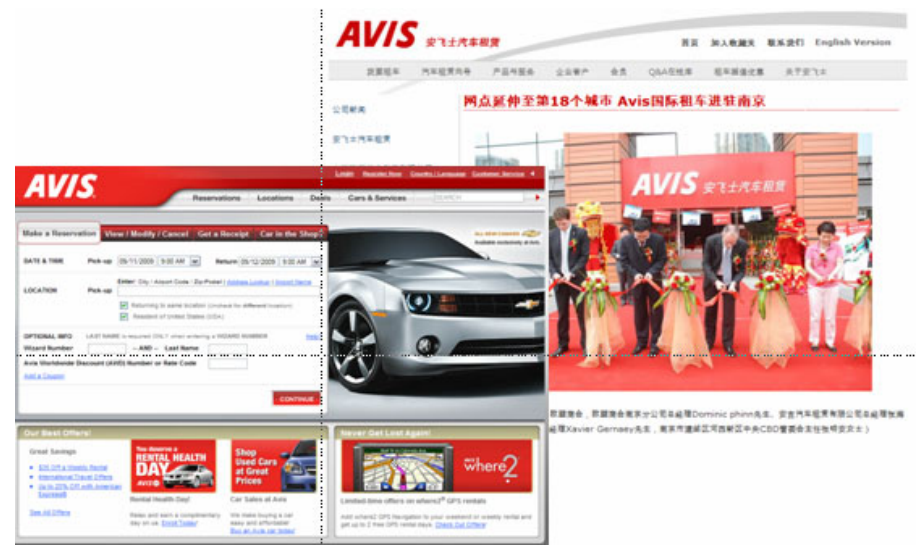

Fig. 2. - AVIS website in the $\mathrm{USA}^{4}$ and in $\mathrm{China}^{5}$

\subsection{Methodology}

We adopted non-predictive interpretive methods [4] used in qualitative research. Qualitative methods are especially appropriate for our study, which aims at identifying various meanings that participants have assigned to CVM. Note that, because of this methodological choice, we did not measure the extent of epistemic effects achieved by CVM in the process of design (which would require that we chose, a priori, which variables could be meaningfully related to epistemic activity in a context that was completely new to participants). Rather, we investigated how participants elaborated and used whatever meanings they associated with CVM while designing metacommunication discourse, and identified recurring elements in this process.

\footnotetext{
${ }^{3}$ From now on we will refer to it as simply "the AVIS website" (http://www.avis.com/).

${ }^{4}$ http://www.avis.com/, last accessed in Jan 3, 2011.

${ }^{5} \mathrm{http} / / /$ www.avischina.com/, last accessed in Jan 3, 2011.
} 
We recruited six participants and asked them to redesign parts of the AVIS website involved in making a car rental reservation with pick-up location in a foreign country. They should have a different cultural background than the American one expressed in the Avis website, good knowledge of HCI design and reading fluency in English. Participants should also have different cultural experience from one another. We believed that new design alternatives elaborated by people with different cultural backgrounds would create clearer contrast for Avis' USA-centered design choices, thus enriching our research context and results.

\subsection{Procedures}

First, the participants listened to a tutorial introducing the cultural viewpoint metaphors (with concepts and examples). Then, they generated re-design alternatives for the AVIS website guided by CVM and by a scenario of use and requirements. In the scenario, the participant supposedly works in a re-design Project for AVIS. The company wants to minimize problems that their customers have reported when using a rental car in a foreign country. Problems stem from cultural differences that play a role when driving a car. The participant's task is to propose re-design alternatives to improve cross-cultural contact by communicating cultural diversity guided by CVM. The targeted user is an American residing in the USA, who makes a car reservation on the AVIS website and chooses a foreign country location for car pick-up. This location depended on the participant's cultural experience (see Table 2).

Table 2. Participants' cultural background and corresponding targeted user

\begin{tabular}{|l|l|l|l|}
\hline Id & Nationality & $\begin{array}{l}\text { Participants' Cultural } \\
\text { background explored in } \\
\text { the experiment scenario }\end{array}$ & $\begin{array}{l}\text { Target User: } \\
\text { an American residing in } \\
\text { the USA who chooses... }\end{array}$ \\
\hline P1.1 & Brazilian & $\begin{array}{l}\text { Studying and working in } \\
\text { England }\end{array}$ & London for car pick-up. \\
\hline P1.2 & Mexican & Living in Mexico & Mexico City for car pick-up. \\
\hline P1.3 & $\begin{array}{l}\text { Brazilian } \\
\text { and Israeli }\end{array}$ & $\begin{array}{l}\text { Studying and working in } \\
\text { Israel }\end{array}$ & Israel for car pick-up. \\
\hline P1.4 & Brazilian & Living in Brazil & Brazil for car pick-up. \\
\hline P1.5 & Brazilian & $\begin{array}{l}\text { Studying and working in } \\
\text { Montreal, Canada }\end{array}$ & Montreal, Canada for car pick-up. \\
\hline P1.6 & Brazilian & $\begin{array}{l}\text { Studying and working in } \\
\text { Toronto, Canada }\end{array}$ & Toronto, Canada for car pick-up. \\
\hline
\end{tabular}

When finished, they participated in a brief individual post-test interview about the experiment. The interview aimed at collecting discourse evidence regarding the designers' perceptions, comments and explanations about: (i) their design alternatives; (ii) the design process, i.e., how the proposed metaphors helped their decisions and reflection about interaction design; (iii) what they found easy and difficult to do; and, (iv) what they learned with the CVM.

Empirical design evidence (the mockups and the participants' discourse) was analyzed in two steps. First, we inspected the kinds of signs used in mockups. We looked for consistency/inconsistency with CVM concepts, and built a semiotic 
reference ( $i$. e. a collection of articulated signs proposed for the interface [5]) to compare with the participants' verbal statements, analyzed in the next step.

We should clarify, however, that our aim was not to analyze the quality of the final design products (i. e. the mockups). These depend more heavily on the participants' technical abilities and talent than on the interpretive processes and reflective perceptions that constitute the focus of our interest. It is the participants' discourse about the re-design activity, as well as their impressions and opinions expressed during the post-test interview, that mattered most at this stage. This material was analyzed using discourse analysis techniques [11]. The analysis consisted of a systematic and iterative exploration of the participants' discourse in order to find out major meaning categories in it.

\subsection{Results}

The results of our experiment pointed at three important facts about these participants' first experience with CVM in a design activity. One of them is related to the form of CVM (how they were presented, described, and illustrated), whereas the other two are clearly related to how CVM can function. The evidence collected suggests that: CVM should be improved to minimize difficulties in understanding the fundamental concepts associated with the approach; CVM achieves considerable epistemic effect on cross-cultural design process; and, CVM helps designers in organizing communication about their intent of promoting intercultural contact.

As already mentioned, this paper focuses only on results regarding the epistemic nature of CVM. By epistemic we mean that it can generate new knowledge, not only in factual terms but also at more abstract and conceptual levels. We reached this conclusion based on four specific subcategories of meanings evidenced in the participants' discourse: a mapping of the design space; an exploration of communicative effects achieved by articulating cultural variables with different metaphors; an increased awareness of the designers' own cultural biases and gaps; and, a kind of mirror effect, when designers placed themselves in the role of recipients of their own design communication. For lack of space, we cannot present a thick description of qualitative data in this paper. Instead, we selected some of the participants' comments to illustrate the kind of data we used in our analysis.

About the first subcategory, CVM guided the participants throughout the re-design process, helping them to focus on culture and to map out the problem space. See below what some of the participants said, translated into English when originally expressed in Portuguese. The participants' identification precedes the selected statements.

P1.1: "I was completely guided by the metaphors". "When I began to feel lost with this metaphor, I looked at this continuous progression, I [then] positioned myself closer to this one". "The continuum, the separated layout of metaphors, reminded me of the differences [among them]."

P1.3: "I could identify the issues that have to do with culture, and the ones that haven't. The ones that haven't were put aside. So I realized that there were things that had to be eliminated [from my design], and things that had to be added."

Second, CVM helped designers to reflect about how to model cultural variables according to each metaphor while elaborating metacommunication. P1.1, for instance, realized that cultural variables generate different levels of difficulty in design: 
P1.1: "The variables of unit of measurement and volume are the most trivial to treat with metaphors. It's a piece of cake! Now, the meaning of the economic car is an important aspect and more difficult than the one I made for the 'foreigner with translator' metaphor, and I used it a lot. And the question about the minimum age to drive a car as a rule of business, [same with] the use of the driver's license."

$\mathrm{P} 1.2$, in turn, realized that the communication about cross-cultural experience may require new forms of representation.

P1.2: "These experiences involve other kind of senses, so the visual representation could be not so effective [as] to hit and impregnate user with the relevant aspects of the cultural values that [the] designer wants to communicate".

Third, difficulties in manipulating cultural variables led participants to face new challenges or problems in cross-cultural design and look for solutions. Here are statements from our participants:

P1.3: "How can we speak of the Israeli culture within the context of the American practice? Certainly, if I had not heard about these metaphors, I would have had difficulty in doing [the activity proposed in the scenario] because I would not have been aware of the problem!'

P1.4: "This helped me by informing better that he is closer [to the other culture]. And this is very important because the website has to be able to inform all the time where he is, to inform him of the context."

Cultural gaps experienced by some of the participants actually helped us to confirm the epistemic potential of CVM in bringing out to the participants aspects of their own knowledge and perceptions regarding other cultures. At least two of them (P1.1 and P1.5) decided to seek for knowledge in another website. P1.5, for instance, said:

P1.5: "Thinking about what would be different for the Canadians, I opened a car rental site from Quebec, which was right there beside that site, to see how they offered their cars for rent, I found their site worse than that of AVIS's. But you can understand a little about the issue with the language. The first language offered by them is English."

Finally, we collected evidence that CVM led designers to put themselves more clearly in the role of recipients of the metacommunication (the users). P1.2 and P1.3, for instance, explained how CVM put them inside the scenario. Suddenly, the target user was not someone far away. Rather, they were thinking of themselves as their own users, or of close friends they know well.

P1.2: "Actually, I was considering myself as a "gringo" who's looking for a car rent in Mexico. Yeah, I realize [that] the point is how the Mexican culture is presented."

P1.3: "I imagined the scene that you describe. I imagined that a friend was going to Israel and would have to rent a car, I imagined that, then, it would help him to understand the questions and for me to be explanatory and bring curiosities from that country."

The participants' discourse excerpts presented above show evidence that CVM was not used to generate the answer to the problem right away, but to increase the participants' own understanding of the problem, explore its implications, generate alternative solutions and evaluate them against each other. 


\section{Conclusions}

Cultural differences around the world raise the challenges of good HCI design. For a number of years the HCI community has been investigating alternatives to enhance the design of cross-cultural systems [2, 3, 6, 14]. Our cultural viewpoint metaphors perspective aims at helping designers to think of how to expose and communicate the very idea of cultural diversity. In this paper we presented results from an empirical study carried out to assess the metaphors' potential for informing and improving the design of cross-cultural applications. The epistemic nature of CVM was evidenced by statements about how they guided participants throughout the re-design process, helping them to focus specifically on culture and to map out the problem space. They led the designers to understand, conceptualize and reflect on their design goals and alternatives to achieve them.

The five cultural viewpoint metaphors have the potential to spark innovative features in design. Although we do not predict that this innovation will happen in every design instance with CVM, it is a fact that new insights have been gained by all participants of the reported experiment. Our approach forces designers to make decisions about strategies to structure communication of intercultural contact opportunities, independently of strategies to recognize and collect culturallydependent content to be delivered. As a result, they can reason about cultural communication and cultural information at different stages of design. In this respect, CVM can be used in combination with other approaches that focus on cultural content, mainly $[6,10,14]$.

Furthermore, evidence collected in this experiment revealed that the application of CVM helps designers gain awareness of their own cultural biases. Through the process of deciding how they want to and should communicate cultural differences, designers get in touch with their culturally-determined assumptions that might otherwise go unnoticed in their design choices, affecting the users' experience in unpredicted or undesired ways. Turning cultural differences into a topic of computermediated designer-user conversations naturally leads designers to position themselves more explicitly with respect to their own cultural values and beliefs. Reflection about one's own position in the process of designing intercultural systems with the aim of promoting contact with foreign cultures is perhaps the most important finding of this experiment. This is a confirmation of the reflective and epistemic effects of Semiotic Engineering discussed elsewhere [5], from which CVM originates.

The results presented here were validated [13] (as is typical in validation of qualitative research) through an exogenous triangulation [4]. This motivates us to carry out new empirical studies to explore the practical effects of designing crosscultural systems with CVM on designers and users.

Acknowledgements. We thank the volunteer designers that participated in our study. Clarisse de Souza and Luciana Salgado thank the National Council for Scientific and Technological Development $(\mathrm{CNPq})$ and the Research Foundation of the State of Rio de Janeiro (FAPERJ) for financial support at different stages of this research project. 


\section{References}

1. Aykin, N.: Usability and Internationalization of Information Technology. Lawrence Erlbaum, New York (2005)

2. Cyr, D.: Modeling Website Design Across Cultures: Relationships to Trust, Satisfaction, and E-Loyalty. J. Manage. Inf. Syst. 24(4), 47-72 (2008)

3. Clemmensen, T.: Towards a Theory of Cultural Usability: A Comparison of ADA and CM-U Theory. In: Kurosu, M. (ed.) HCD 2009. LNCS, vol. 5619, pp. 416-425. Springer, Heidelberg (2009)

4. Cresswell, J.W.: Research Design: Qualitative, Quantitative, and Mixed Methods Approaches, 3rd edn. SAGE Publications, Thousand Oaks (2009)

5. de Souza, C.S.: The semiotic engineering of human computer interaction. The MIT Press, Cambridge (2005)

6. del Galdo, E.M., Nielsen, J.: International Users Interface. John Wiley, New York (1996)

7. Fernandes, T.: Global Interface Design: a Guide to Designing International User Interfaces. Academic Press, New York (1995)

8. Lakoff, G., Johnson, M.: Metaphors We Live By. University of Chicago Press, Chicago (1980)

9. Marcus, A.: International and intercultural user interfaces. In: Stephanidis, C. (ed.) User Interfaces for All: Concepts, Methods, and Tools, pp. 47-63. Lawrence Erlbaum, Mahwah (2001)

10. Marcus, A., Gould, E.W.: Crosscurrents: Cultural dimensions and global Web userinterface design. Interactions 7(4), 32-46 (2000)

11. Nicolaci-da-Costa, A.M., Leitão, C.F., Romão-Dias, D.: Gerando conhecimento sobre os homens, mulheres e crianças que usam computadores: algumas contribuições da psicologia clínica. In: Symposium on Human Factors in Computers Systems, IHC 2001, Florianópolism Anais SBC, pp. 120-131 (2001)

12. Salgado, L.C.C., de Souza, C.S., Leitão, C.F.: Conceptual Metaphors for Designing MultiCultural Applications. In: Proceedings of the 4th Latin American Conference on HumanComputer Interaction. IEEE Publications, Piscataway (2009)

13. Salgado, L.C.C.: Doctoral Thesis: Cultural Viewpoint Metaphors to explore and communicate cultural perspectives in cross-cultural HCI design. Departamento de Informática, PUC-Rio (to appear)

14. Shen, S., Woolley, M., Prior, S.: Towards culture-centred design. Interacting with Computers 18(4), 820-852 (2006) 